\title{
DOWNSCALING TROPICAL CYCLONES FROM GLOBAL RE-ANALYSIS AND SCENARIOS: STATISTICS OF MULTI-DECADAL VARIABILITY OF TC ACTIVITY IN E ASIA
}

\author{
Hans von Storch, Frauke Feser and Monika Barcikowska ${ }^{1}$
}

\begin{abstract}
An atmospheric regional climate model was employed for describing weather of $\mathrm{E}$ Asia for the last decades as well as for the coming century. Re-analyses provided by Global National Center for Environmental Prediction - National Center for Atmospheric Research (NCEP-NCAR) for the past six decades, as well a scenario generated by the ECHAM5/MPI-OM model were dynamically downscaled to a $50 \mathrm{~km}$ grid using a state-of-the-art regional climate model (CCLM). Using an automated tracking system, all tropical cyclones (TCs) are identified in the multi-decadal simulations. The different analysis products of TC-statistics were found to differ strongly, also in recent times when the data base was good, so that in the long-term statistics 1950-2010 inhomogeneities mask real climatic variations. The 1948-2009 time series of the annual numbers of TCs in the NCEP-driven simulation and in the JMA best track data (BT) correlate favourably. The number is almost constant, even if there is a slight tendency in BT to show less storms, whereas CCLM shows somewhat more storms, which became more intense. The ECHAM5/MPI-OM-driven scenario simulation, subject to 1959-2100 observed and projected greenhouse gas concentrations, shows a reduction of the number of storms, which maintains a stationary intensity in terms of maximum sustained winds and minimum pressure. Thus, BT-trends and downscaled trends were found to be inconsistent, but also the downscaled trends 19482009 and the trends derived from the A1B-scenario were different.
\end{abstract}

Keywords: typhoon statistics; typhoon scenarios; downscaling; best track data

\section{INTRODUCTION}

Tropical cyclones present the major geo-risk in East Asia; therefore knowledge about the statistics of such storms, commonly called typhoons, is needed for reducing societal vulnerability. This knowledge comprises the degree of interdecadal variability (Chu et al., 2010), the assessment of recent trends (Ren et al., 2006) and projections for possible future developments. An important detail is to what extent recent trends are consistent with trends described as possible for the coming 100 years (c.f., Bhend and von Storch, 2007).

Some claim that storm intensity has increased in the Northwest Pacific (Emanuel (2005), Webster et al. (2005), Elsner et al. (2008)), while others point to large interdecadal variations (Chan, 2006; Kim et al., 2006; Lau et al., 2008) or inhomogeneities ${ }^{2}$ (Knaff and Zehr, 2007; Ren et al., 2010) in the data extending cross the past decades, or even found small or no trends Klotzbach (2006).

Obviously, the issue of changing typhoon statistics - number, intensity, and regional distribution need more attention. We contribute to this analysis by employing a dynamical downscaling strategy, making use of global re-analyses and of global scenario simulations on the effect of elevated atmospheric greenhouse gas concentrations. To do so we force the large-sale analysed or simulated state via a technique called "spectral nudging" (von Storch et al., 2000) upon the limited area model CCLM (Feser and von Storch, 2008a,b; Tang et al., 2010), and integrate the model for several decades. In this way, a consistent description of typhoon activity is generated. The success of this exercise may be compromised, first of course due to insufficiencies of the model itself, by inhomogeneities in the description of the large-scale dynamics in the re-analysis (for instance related to the advent of satellite data in the 1970s, see Kistler et al., 2001).

Any attempt of reconstructing the changing statistics of tropical storms needs a reliable reference for validating the model. The best track data, prepared by several weather services, are an obvious choice, but it turns out that they suffer from severe inhomogeneities (Ren et al., 2010). We deal with his issue in Section 2.

${ }^{1}$ Institute of Coastal Research, GKSS Research Center, Geesthacht, 21502, Germany, and CLISAP Center of Excellence, University of Hamburg, Hamburg 20146, Hamburg, Germany

${ }^{2}$ Inhomogeneities refer to changes in the statistics of recorded weather characteristics, which are due to local effects, in the instrumentation, the observational practice, the analysis or the immediate environment, see e.g., Jones (1995) 
The model set-up is described in Section 3, the outcome of the "reconstruction" simulation in Section 3, and that of the scenario simulation in Section 4. A discussion in Section 5 concludes the article.

\section{REFERENCE DATA}

As reference for comparing the limited area model CCLM, the so-called Best Track data provided by the Chinese (CMA) and Japanese (JMA) weather services as well by the Joint Tropical Cyclone Warning Center (JTWC) are an obvious option. The Best-tracking data are temporally inhomogeneous as data availability and techniques have changed over time (Ren, 2010) - mostly due to commencing and ending (1987) of reconnaissance flights and the availability of satellites since the 1970s. Additionally, procedures and data availability differ at each agency. The problem is illustrated in Figure 1a, which shows for JMA the annual number of TCs, which is stationary, the annual minimum pressure along the tracks (red diamonds) of all TCs within a year, which show a marked increase (less intense) since 1980, and a massive decline of the maximum annual 6-hourly pressure decrease (blue rings) from values of up to $93 \mathrm{hPa} / 6$ hours in 1953 to almost constant values of $15 \mathrm{hPa} / 6$ hours in the latest part of the record.

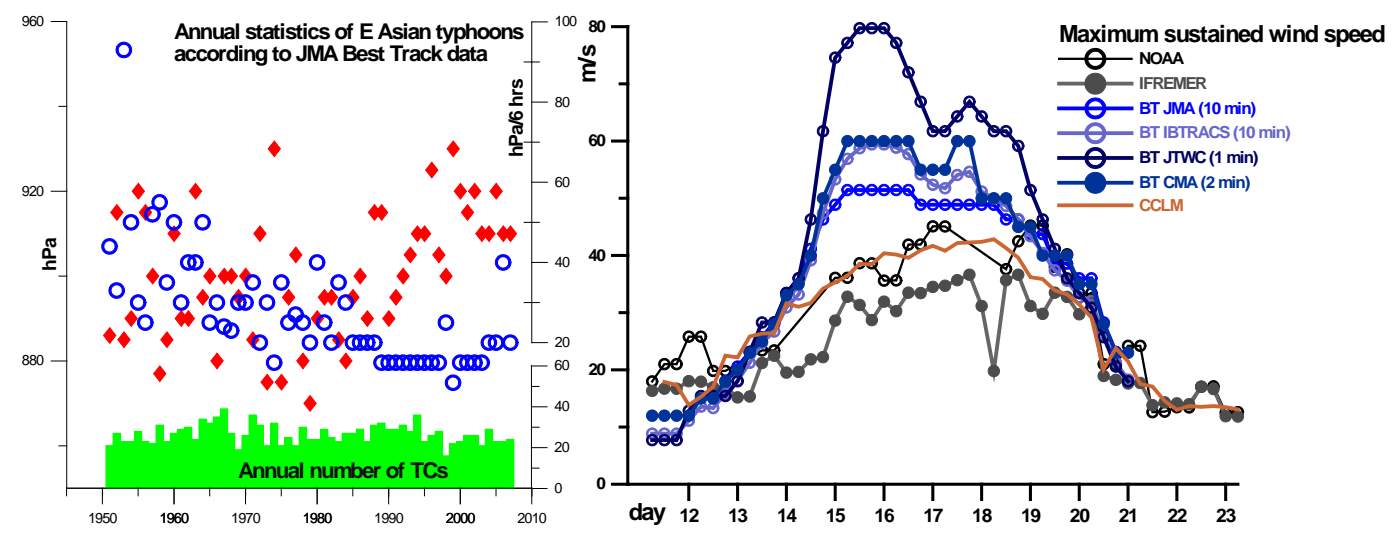

Figure 1.

a/left: Annual statistics derived from JMA Best Track data - in green (right lower axis) the number per year; blue open rings: maximum pressure fall within 6 hours (right upper axis; $\mathrm{hPa}$ ), and red diamonds: minimum pressure along all tracks (left axis; hPa).

b/right: the sustained maximum wind speed $(1,2$ or 10 minute averages; $\mathrm{m} / \mathrm{s})$ of storm Dianmu from 2004 as described by different Best Track data (JTWC, CMA, JMA, IBTrAcs - blue; NOAA, IFREMEER - grey; and CCLM - brown; see text). The differences, apart of those with CCLM, describe the uncertainty in the analysis of such storms.

A derived product is "International Best Track Archive for Climate Stewardship merging" (IBTrACS), which merges a number of best track data sets, for NW Pacific, namely those compiled by: CMA-Shanghai Typhoon Institute, JTWC and Hongkong Observatory. Likely this suffers from the same inhomogeneities as the original data.

Since 2000, JMA is performing a postseason "best tracking" analysis of tropical cyclones operating the Regional Specialized Meteorological Centres (RSMCs) for the NW Pacific. These RMSCs have been designated by World Meteorological Organization (WMO) for forecasting and monitoring TC development and movement for their area of responsibility.

A NOAA-dataset describes wind conditions at the sea surface, with a 6-hourly on a $0.25^{\circ}$ grid, extending from 1987 to present. This data set is generated by blending satellite observations: special sensor microwave imager onboard of DMSP SSMI F08, F10, F11, F13,F14 F15; and active scatterometers on board of TMI, QuikSCAT and AMSR-E with wind directions given by NCEP Reanalysis-2 (NOAA, 2010). A similar product has been generated at IFREMER, named "Near Real Time Blended Surface Winds", which describes marine winds on a $0.25^{\circ}$ global oceans grid, every 6 hours since 2004. It blends operational ECMWF wind direction analyses with scatterometer data from 
QuikSCAT and Special Sensor Microwave data from (SSM/I) onboard DMSP satellites F13, F14, and F15. These two data sets can not be used to assess multi-decadal trends, as they are too short for this purpose, but they may be used to assess the quality of the BT data and the "reconstructions".

For one case, the storm Dianmu (13-21 June 2004), this is done in Figure 1b, which shows best track, NOAA, IFREMER and CCLM maximum sustained wind speeds. In this case, and others not shown, the differences between the analyses are substantial; NOAA and IFREMER have usually smaller wind speeds than the Best Track data; also the CCLM wind speeds are at the lower end, with wind speeds usually underestimated by the model.

We conclude

1. "Best track" data are affected by inhomogeneities related to changing observational and analytical procedures in the course of time (see also Ren, 2010)

2. Different agencies produce different "best track" data.

3. The comparison with satellite-based data analyses reveals further differences in wind speeds. "Best track" data may provide an overestimate or satellite-based data an underestimate.

\section{DYNAMICAL DOWNSCALING}

We use the state-of-the-art atmospheric limited area model CCLM (www.clmcommunity.eu), which is the Climate version of the operational weather forecast model LM (Rockel et al. 2008, Steppeler et al., 2003) of the German Weather Service. It runs with standard parameterizations for physical processes; for convection the Tiedtke parameterization scheme was selected for this study. The CCLM takes the SST from the NCEP reanalyses (or ECHAM5/MPI-OM scenario simulation) after interpolation to the according CCLM grid.

In this study, a vertical grid of 32 layers is used, and a horizontal grid of about $50 \mathrm{~km}$. In addition to the usual forcing via the lateral boundaries a spectral nudging technique was applied for the whole model domain (von Storch et al., 2000). This method adds nudging terms to the results of the RCM which 'nudge' the regional solution towards the forcing global model. The method was exclusively used for horizontal wind components, starting at a height of $850 \mathrm{hPa}$, and with increasing strength with height. Below $850 \mathrm{hPa}$ no spectral nudging is applied. Thereby we prevent the regional model from deviating from the global model for large spatial scales. For the NCEP reanalyses and for the ECAHM5/MPI-OM spatial scales larger than about $800 \mathrm{~km} 4$ were considered reliably resolved and these spatial scales were nudged in the RCM simulation.

We have previously examined the performance of the model for a single case (Feser and von Storch, 2008a), and later for an ensemble of storms 12 typhoons between May and October of the western North Pacific typhoon season 2004 (Feser and von Storch, 2008b). We found that regional models improve simulated typhoon developments from global forcing reanalyses data by giving lower core pressure and higher wind speeds and more realistic precipitation patterns, but these values were found to be smaller than in JMA best track data. A double-nesting with a higher resolution of about $18 \mathrm{~km}$ did not significantly improve the results.

To identify the single typhoon events, a tracking algorithm was used that detects pressure lows and their movement in a medium-pass filtered air pressure field (for details, see Feser and von Storch, 2008b). Furthermore, only minima travelling farther than $200 \mathrm{~km}$ and existing for at least 8 hours were considered TCs.

The model was run twice, once with NCEP reanalysis-1 lateral boundary conditions and spectral nudging for 1948-2009 (see below), and once with an A1B global scenario prepared with the global ECHAM5/MPI-OM climate model (see below).

\section{RECONSTRUCTION THROUGH DOWNSCALING OF NCEP RE-ANALYSES}

The CCLM simulates realistic looking typhoons (Feser and von Storch, 2008a), which seem to be too weak (Figure 1b). An example of the added value provides Figure 2, which shows for one case (Dianmu on 21. June 2004) maps of wind speed according to the NOAA analysis (see above), the driving coarse grid NCEP reanalysis and the CCLM product - in CCLM the storm is considerably stronger and more focussed than in NCEP, while having an intensity which compares about with the NOAA analysis. 


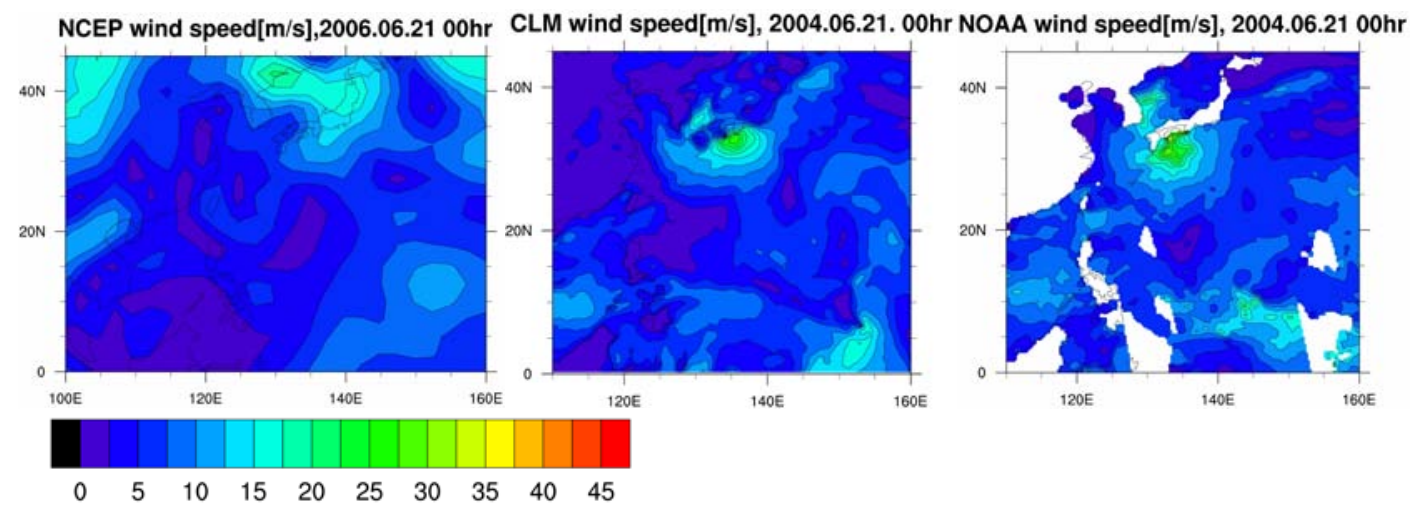

Figure 2.

Maps of wind speeds of typhoon Dianmu on 21 June 2004, 00 UTC (see also Figure 1b) according to the driving NCEP reanalysis (left), the CCLM downscaled result, and for reference the estimate of the NOAA wind product (right). The scale applies for all three diagrams. Units: $\mathrm{m} / \mathrm{s}$

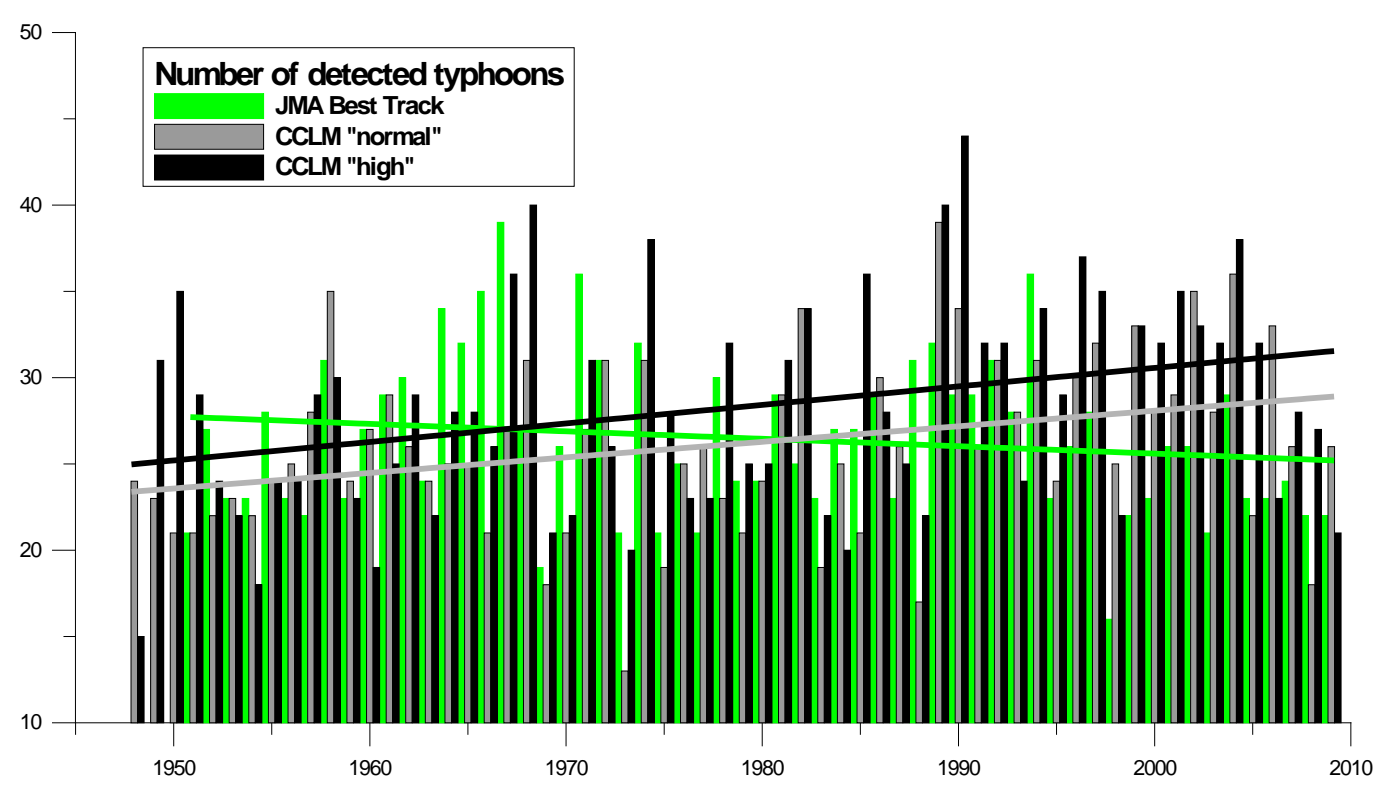

Figure 3. Number of annually detected typhoons according to the operational JMA best track analyses 19512009, and according to two simulations with CCLM downscaling NCEP 1948-2009, one with "standard" latent heat surface fluxes; one with enhanced latent heat fluxes.

The tracking algorithm has been tuned so that on average the same number of typhoon tracks is found as in the JMA analysis. The total count, together with the count according to JMA, is shown in Figure 3. In that diagram a second simulation is shown, namely one in which the latent heat surface flux is strongly increased. The effect of this change of one of the key parameterizations leads to more storms, but neither the inter-annual variability nor the trend are affected.

We find the inter-annual variability of the curves correlating fine. The years with only a few storms in the best track data set are the same as in CCLM, in both formulations, and the years with many TCs in JMA are also the same in CCLM. This is also demonstrated by Figure 4, which shows for two extreme seasons - 1994 with as much as 36 JMA best track TCs, whereas 31 in CCLM, and only 16 in 1998 according to JMA, and 25 according to CCLM - all detected storm tracks.

Interestingly the trends in the number of storms do not fit. In JMA there is a slight decrease, whereas in the two simulations, on average more storms are formed in recent years. It seems that this is 
mainly due to changes in the time since about 1980, which would point towards inhomogeneities related to the advent of satellite-based data.
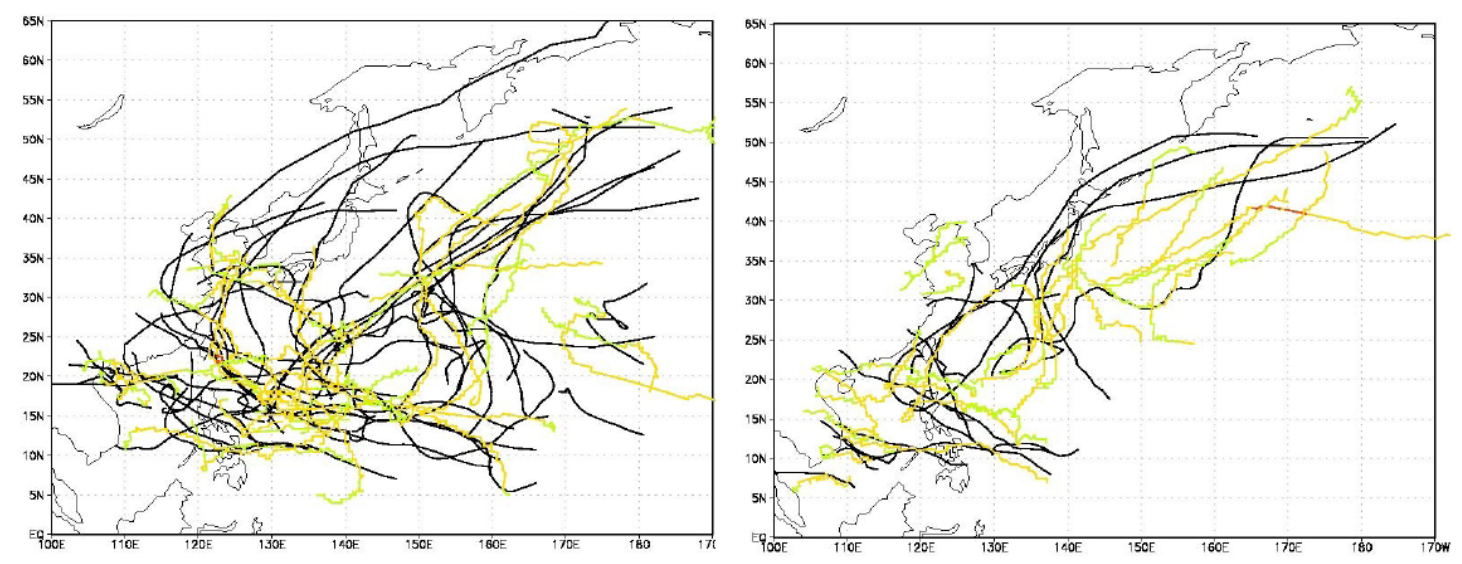

Figure 4

Recorded best tracks in JMA data base (black) and detected tracks in CCLM reconstruction simulation (standard set-up; yellow) in year with many TCs (1994, left) and in year with few TCs (1994).

We conclude that

4. long-term trends in the number of TCs according to the CCLM downscaling of NCEP and in the JMA best track differ markedly, even if the year to year variation correlates well;

5. in CCLM, some intensification of TC activity takes place mainly since about 1980;

6. in JMA-best track, some weakening takes place, possibly stronger since about 1980.

\section{DERIVING POSSIBLE FUTURES THROUGH DOWNSCALING OF GLOBAL SCENARIO SIMULATION}

Finally, one scenario simulation done with the global ECHAM5-MPIOM subject to an A1B emission scenario has been downscaled for 1959-2100. The results in terms of number of storms, of maximum sustained wind speed of all TCs within a year as well as minimum surface air pressure along all tracks within a year are plotted in red in Figures 5, 6 and 7 - together with the same statistics for the reconstruction simulation presented before, given in grey.

Of course, the two statistics, reconstruction and scenario, should not correlate well on the year-toyear basis during the joint years 1960-2100. This is so, because the assignment of a year $\mathrm{N}$ in the scenario simulation is done only with respect to the atmospheric CO2 concentration in the year $\mathrm{N}$, whereas in case of the reconstruction the assignment $\mathrm{M}$ is based on the large scale circulation of $\mathrm{M}$ and the CO2 concentration of $\mathrm{M}$. Thus, the natural fluctuation overlaid any CO2 signal in the scenario simulation is independent of the natural fluctuation which actually took place in the years 1960-2008.

The scenario exhibits a trend towards less TCs; in the end of the $21^{\text {st }}$ century the number would be only about $2 / 3$ of what it was at the end of the $20^{\text {th }}$ century (Figure 5 ). At the same do the indicators of intensity, maximum wind speed and minimum air pressure show hardly a chance (Figures 6 and 7), which may mean that there are less weaker TCs but the same number of strong storms as before.

The recent trends, derived from the reconstruction are not consistent with the projections of the scenario: The number in recent years is increasing according to the downscaled re-analysis, but in the scenario this number is going down (Figure 5). Similarly, the intensification in recent years, as documented by a falling minimum air pressure (Figure 6) and a rising maximum wind speed (Figure 7), can not be seen as an anticipation of what the scenario projects as possible future, namely stationarity in terms of intensity.

\section{We conclude}

7. Number and intensity in reconstructions 1948-2009 is increasing. 
8. Number in scenario A1B is slightly decreasing, while intensity is almost stationary. Note - only one scenario.

9. Thus, the scenario can not be seen a continuation of recent changes.

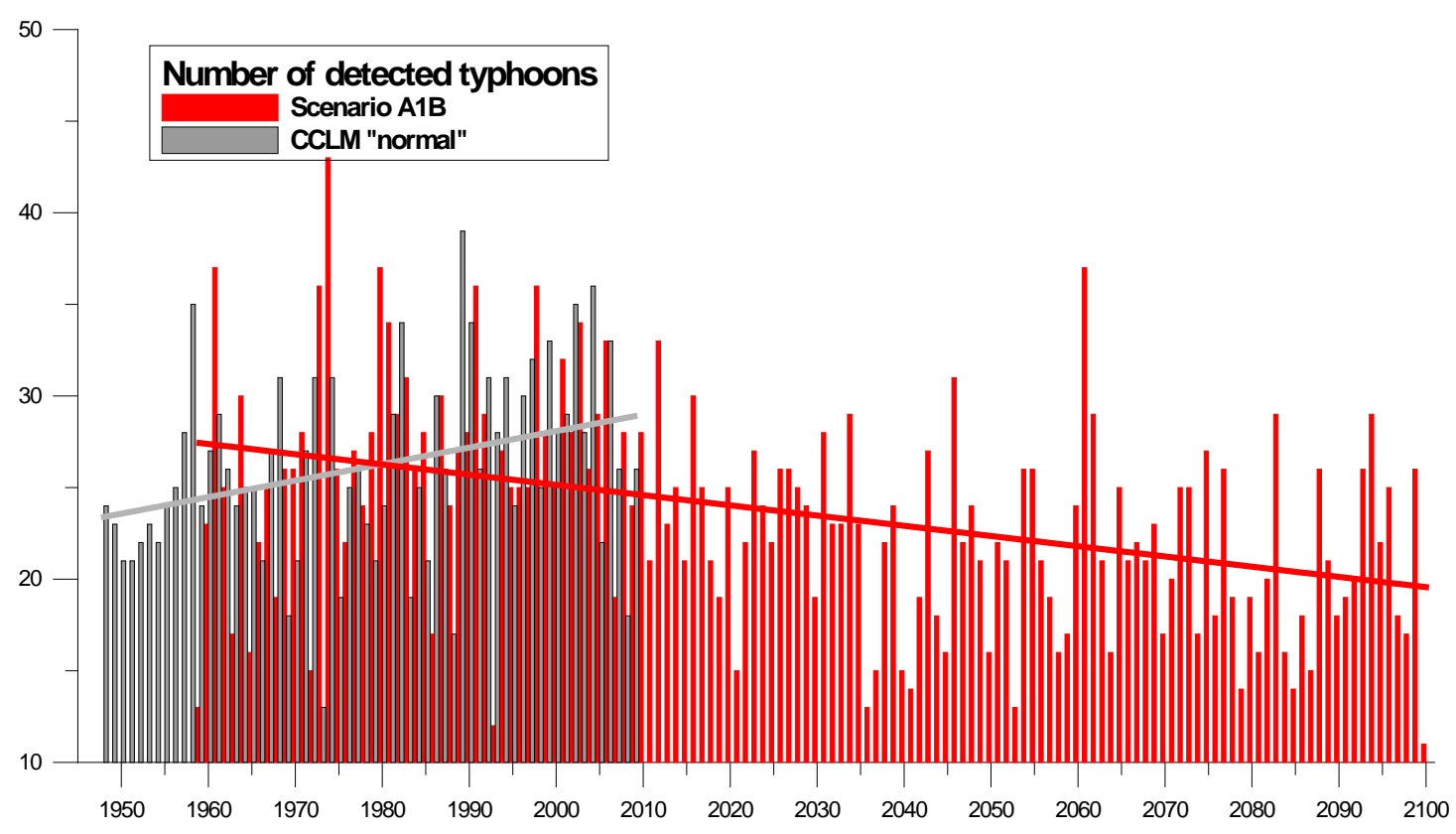

Figure 5

Annual number of detected TCs in downscaled simulations - of 1948-2009 NCEP re-analyses (grey) and 1959-2100 MPI-OM A1B scenario (red). The lines describe linear trends.

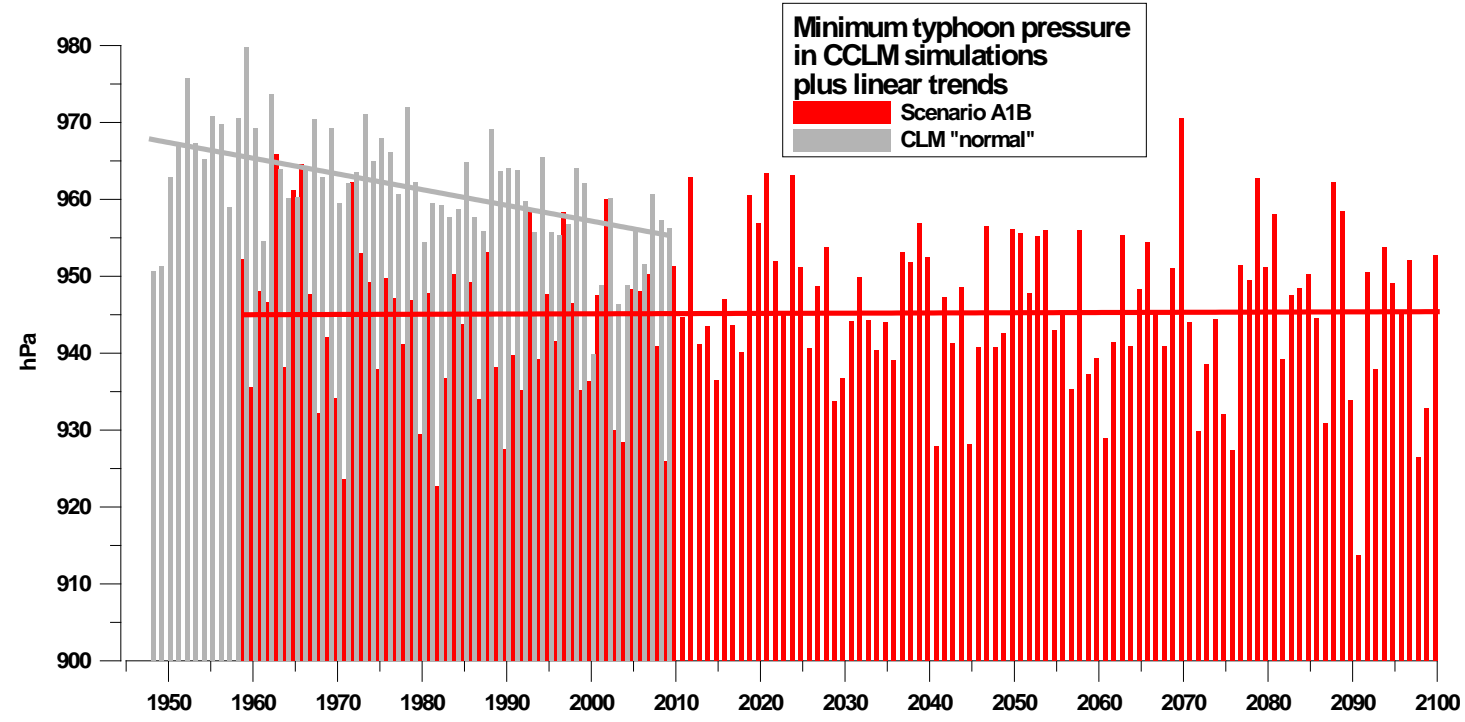

Figure 6

Annual minimum air pressure along tracks of detected TCs in downscaled simulations - of 1948-2009 NCEP re-analyses (grey) and 1959-2100 MPI-OM A1B scenario (red). The lines describe linear trends. 


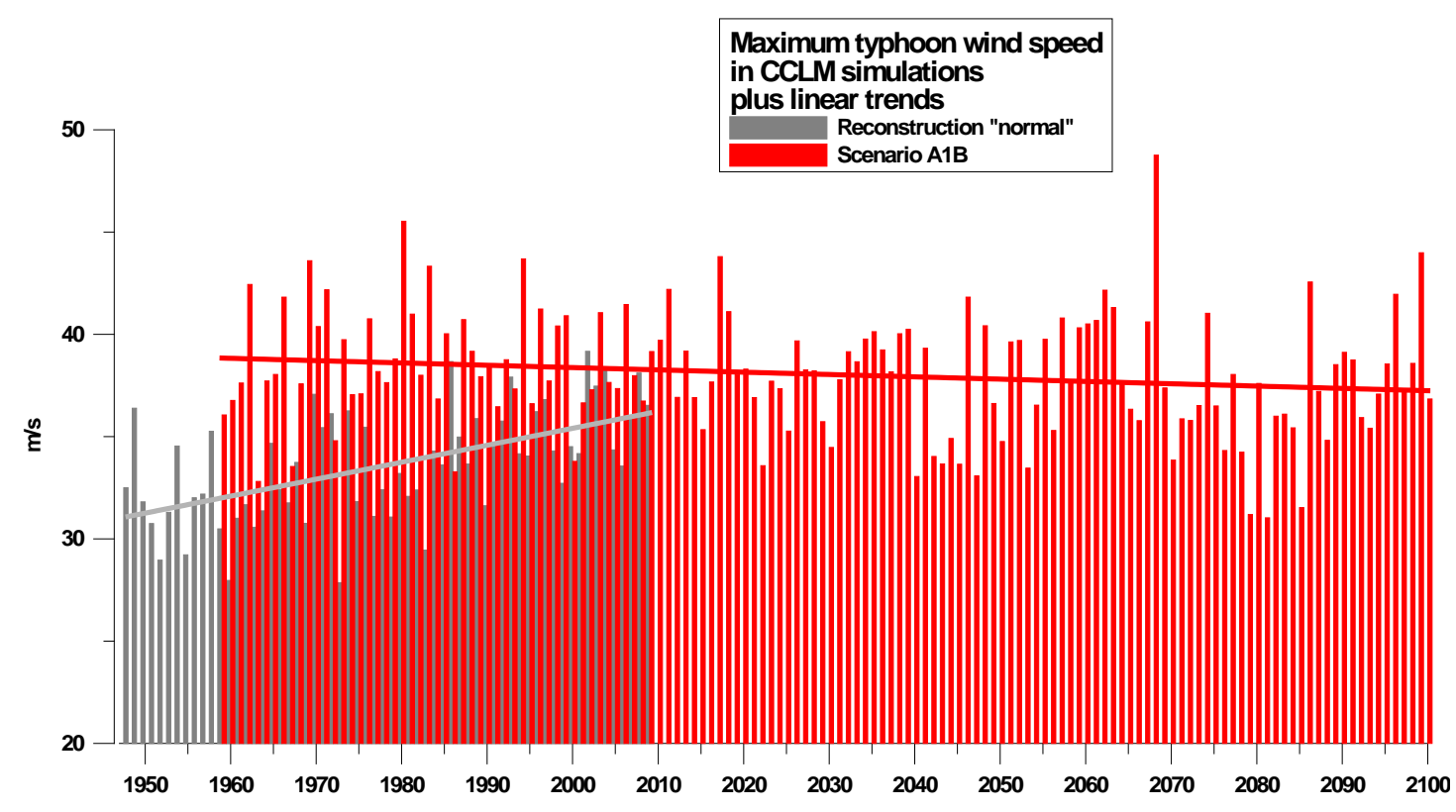

Figure 7

Annual maximum sustained wind speed along tracks of detected TCs in downscaled simulations - of 19482008 NCEP re-analyses (grey) and 1960-2100 MPI-OM A1B scenario (red). The lines describe linear trends.

\section{DISCUSSION}

The present result show an encouraging result, namely that downscaling of both re-analysis as well as global coarse resolution scenario simulations is doable and delivers reasonable descriptions of tropical cyclone (TC; typhoon) activity in East Asia. The storms may be a bit too weak, but given the uncertainty of the observational evidence about TCs, the model result is not perfect but somehow reasonable.

Otherwise a number of puzzles are left. The main point is: the three pieces of our analysis, observational evidence 1951-2010 as gathered in best track data sets, the reconstruction 1948-2009 obtained trough downscaling of NCEP re-analysis, and the 1959-2100 projection, do not fit together. The best track data indicate a decline of TC activity; the reconstruction an increase in recent years, and the scenario projects a further decline.

There are a number of weak or possibly weak elements in our pieces, namely

a) the inhomogeneity of the best track data sets, as documented by Ren et al. (2010);

b) the inhomogeneity in the driving NCEP reanalysis, as documented by Kistler et al. (2001), which may cause unrealistic trends in the downscaled end-product;

c) the projection into the future should be done with an ensemble of scenarios simulations, using different global models and different emission scenarios;

d) systematic errors in the global GCMs, which may lead to a distorted response of TC activity to elevated greenhouse gas concentrations.

e) other factors, such as increasing regional aerosol loads, may have played a role in the changes of the past decades, which will cease to play a role in future changes.

Finally, it may be that the CCLM model physics is insufficient to describe the complex dynamics which end up in changing TC statistics. 


\section{REFERENCES}

Bhend, J., and H. von Storch, 2007: Consistency of observed winter precipitation trends in northern Europe with regional climate change projections, Clim. Dyn.31: 17-28. DOI 10.1007/s00382-0070335-9

Chan, J.C.L., 2006: Comment on "Changes in Tropical Cyclone Number, Duration, and Intensity in a Warming Environment”, Science, 311, 1713, doi:10.1126/science.1121522.

Chu, P.-S., Xin Zhao, X, and J.-H. Kim, 2010: Regional typhoon activity as revealed by track patterns and climate change. Elsner. J.B., (ed.): Hurricanes and Climate Change, Vol 2, Springer, 2010.

Emanuel, K., 2005: Increasing destructiveness of tropical cyclones over the past 30 years. Nature, 436, 686-688, doi:10.1038/nature03906.

Elsner, J.B., J.P. Kossin, and T.H. Jagger, 2008: The increasing intensity of the strongest tropical cyclones. Nature, 455, 92-95, doi:10.1038/nature07234.

Feser, F., and H. von Storch, 2008a: A dynamical downscaling case study for typhoons in SE Asia using a regional climate model. Mon. Wea. Rev. 136, 1806-1815

Feser, F.,and H. von Storch, 2008b: Regional modelling of the western Pacific typhoon season 2004, Meteor. Z. 17, 519-528. doi 10.1127/0941-2948/2008/0282

Jones, P.D., 1995: The instrumental data record: Its accuracy and use in attempts to identify the " $\mathrm{CO}_{2}$ Signal". In: H. von Storch and A. Navarra (eds) Analysis of Climate Variability: Applications of Statistical Techniques, Springer Verlag, 53-76

Klotzbach, P.J., 2006: Trends in global tropical cyclone activity over the past twenty years (19862005). Geophys Res. Lett., 33, L10805, doi:10.1019/2006GL025881.

Kim, J.-H., C.-H. Ho, M.-H. Lee, J.-H. Jeong, and D. Chen, 2006: Large increase in heavy rainfall associated with tropical cyclone landfalls in Korea after the late 1970s. Geophys. Res. Lett., 33, L18706, doi:10.1029/2006GL027430.

Kistler, R., E. Kalnay, W. Collins, S. Saha, G. White, J. Woollen, M. Chelliah, W. Ebisuzaki, M. Kanamitsu, V. Kousky, H. van den Dool, R. Jenne and M. Fiorino, 2001: The NCEP/NCAR 50year reanalysis. Bull Amer. Meteor. Soc. 82: 247-267

Knaff, J.A., and R.M. Zehr, 2007: Reexamination of tropical cyclone wind-pressure relationships. Wea. Forecasting, 22, 71-88

Lau, K.-M., Y.P. Zhou, and H.T. Wu, 2008: Have tropical cyclones been feeding more extreme rainfall? J. Geophys. Res., 113, D23113, doi:10.1029/2008JD009963

NOAA, 2010: NOAA/NCDC Blended 6-hourly 0.25-degree Sea Surface Winds http://www.ncdc.noaa.gov/oa/rsad/blendedseawinds.html

Ren, F., G. Wu, W. Dong, X. Wang, Y. Wang, W. Ai, and W. Li, 2006: Changes in tropical cyclone precipitation over China. Geophys Res. Lett. 33, L20702, doi:10.1029/2006GL027951

Ren, F., Liang, J., Wu, G., Dong,W. and X. Yang, 2010: Reliability Analysis of Climate Change of Tropical Cyclone Activity in the Northwest Pacific. J. Climate, submitted

Rockel, B, A. Will, and A. Hense, 2008: The Regional Climate Model COSMO-CLM (CCLM). Editorial, Meteor. Z., 12, 4, 347-348.

Steppeler J., G. Doms, G., U. Schättler, U., Bitzer, H. W., Gassmann, A. Damrath, U. and G. Gregoric, 2003: Meso-gamma scale forecasts using the nonhydrostatic model LM. - Atmos. Phys. 82, 75-96.

Tang, J., S. Song and J. Wu, 2010: Impacts of the spectral nudging technique on simulation of the East Asian summer monsoon. Theor. Appl. Climatol. 101, 41-51, DOI 10.1007/s00704-009-0202-1

Webster, P.J., G.J. Holland, J.A. Curry, and H.-R. Chang, 2005: Changes in tropical cyclone number, duration, and intensity in warming environment. Science,309, 1844-1846 